\title{
Performance Study of Thin Film Composite Polyamide Membranes in Remediation of Nitro-phenols from Water
}

\author{
K. Yogesh ${ }^{1}$, K. M. Popat ${ }^{2}$, H. R. Brahmbhatt ${ }^{3}$, B. Ganguly ${ }^{4}$ \& A. Bhattacharya ${ }^{5 *}$ \\ ${ }^{1-5}$ Reverse Osmosis Discipline, Central Salt and Marine Chemicals Research Institute \\ Bhavnagar-364002, Gujarat
}

INDIA

\begin{abstract}
Apart from the desalination activities, polyamide membranes spread their wings in different separation arena (viz. removal of organic pollutants, pesticides). The separation abilities of the membranes are basically involved in their compositions as well as nature of the solutes. The study brings to light that the removal of the two isomers of the nitrophenols are based on their orientation (viz. dipolemoment). The prepared membrane compositions are also very interesting to study to be dealt herewith. Molecular sizes and their dipole moments of the corresponding nitrophenols are calculated by quantum chemical method. The rejection performance of the phenol compounds for the same membranes are in the following order: 2-nitro phenol > 4-nitro phenol > phenol.
\end{abstract}

Keyzords: Membrane, rejection, nitrophenol, polarity, molecular weight, molecular volume

\subsection{INTRODUCTION}

The reverse osmosis (RO) and nanofiltration (NF) membranes are the subject of attention in these days especially in the removal of pesticides and low molecular weight pollutants [1-4]. In the thin film composite RO membranes, the polyamide layer is formed by interfacial polymerization of m-phenylene diamine (MPD) and trimesoyl chloride (TMC), whereas piperizine (PIP) and TMC form the polyamide layer of NF membrane over the polysulfone membrane [5]. The active membrane surface layer usually consists of negatively charged residual carboxyl group in the trimesoyl chloride moiety. In our previous work, we examined the rejection properties of low pressure reverse osmosis membranes for the chloro-phenolic pesticides and it was observed that higher desalting membranes reject more efficiently. [6].

Here, in this study, performance of the TFC membranes made of piperizine and m-phenylene diamine and with their mixture with trimesoyl chloride (TMC) in the removal of nitrophenols has been performed. Nitro phenols are chosen for this experimentation as it is one of the man-made chemicals that can break down in water and soils. Nitro phenols are favored in the production of

\footnotetext{
* Correspondence to: A. Bhattacharya (tel: 91-278-2567760, fax-91-0278- 2566511, email: bhattacharyaamit1@ rediffmail.com)
} 
fungicides, dyes, paint coloring as well as drugs. Nitro phenols are considered cardiovascular or blood toxicant, neuro toxicant as well as skin and sense organ toxicant. The membrane separation abilities are dependent upon various factors, e.g. nature of the menbrane, molectir of the solutes (e.g. polarity). The details of the performances of different commercial membranes regarding the separation of the pesticides are enlisted in the recent review [7]. The limitations of the earlier reports regarding the remediation of pesticides polluted water are that the performances are not explained in the perspectives of the membrane chemistry, as the compositions of the membranes in most of the cases are concealed. In the present investigation, three types of membranes are prepared by varying the compositions of the reactants of the interfacial polymerization on the same polysulfone substrate. The objective of the study is to establish the relationship between the performanc the permeation solutes as well as the chemistry of the membrane. The remediation performances of two different nitrophenol isomers are also another objective of the investigation.

\subsection{METHODS AND THEORY}

\subsection{Materials and Instruments}

Polysulfone (Udel, Mw 35 000), dimethylformamide (Merck) and sodium lauryl sulfate were used to prepare the asymmetric membrane. m-phenylene diamine (Lancaster) and trimesoyl chloride
(Lancaster) were used for interfacial polymerization. Phenol (Ranbaxy, India) and nitrophenols SRL (India) were used in the membrane rejection measurements. Reverse osmosis treated water was used in the experiment.

Membrane performance experiments were carried out in laboratory made pressure cell. The general details of the set up were sketched elsewhere [3]. The membrane rejection experiments with sodium chloride, magnesium sulfate and chosen phenol and nitrophenols were of the short run type, each lasting for about $3 \mathrm{~h}$. They were carried out at laboratory temperature and operating pressure of lasting
$1 \mathrm{Mpa}$.

The salt rejection measurement was done by their conductivity relationship, as concentrations follow direct relationship. The concentrations of the solute organics were measured by HPLC analysis.

\subsection{Methods}

The polymeric solution, ( $15 \% \mathrm{w} / \mathrm{w}$ in dimethyl formamide) casted on the non-woven polyester fabric ( $1 \mathrm{~m}$ width), controlling the thickness, was dipped into the non-solvent bath (here water mixed with sodium lauryl sulfate) using a prototype casting machine. Sodium lauryl sulfate concentration was maintained at $10 \mathrm{gm} / \mathrm{lit}$. Sodium lauryl sulfate was used in the gelling bath to control the uniformity of pores and also to improve antifouling properties of the membrane. It was dipped instantaneously into non-solvent bath after casting the membrane. The thickness is $\sim 60 \mu \mathrm{m}$ throughout the cast polysulfone membranes.

The asymmetric polysulfone membranes $(20 \mathrm{~cm} \times 15 \mathrm{~cm})$ were coated with aqueous m-phenylene diamine solution. After removing the excess amount of diamine solution, the membrane was then immersed into TMC solution (in hexane) for the interfacial polymerization. The coated membranes were cured at temperature $85-90^{\circ} \mathrm{C}$. The reaction between diamine and trimesoyl chloride formed $\mathrm{CONH}-$ bond and resulted in cross-linked polyamide structure on polysulfone. The details of the reactants used in interfacial polymerization are displayed in the Table 1.
Table 1 Concentration of reactants used in interfacial composition

\begin{tabular}{lcc}
\hline Membrane & Diamine MPD $:$ PIP(\%) & Trimesoyl chloride (\%) \\
\hline Memb-I & $2: 0$ & 0.1 \\
Memb-II & $1: 1$ & 0.1 \\
Memb-III & $0: 2$ & 0.1 \\
\hline
\end{tabular}

Preparation of phenol solutions: Different phenol solutions were prepared in aqueous medium $(25 \mathrm{mg} / \mathrm{l})$ and $(50 \mathrm{mg} / \mathrm{l})$

Analysis: The phenol concentrations were analysed with high performance liquid chromatography Anthod under the following conditions: Column: Nucleosil C 18 (HPLC) using the direct injection method under the following conditions: Column: Nucleosil C 18 (Supelco) $250 \mathrm{~mm} \times 4.6 \mathrm{~mm} \times 5 \mu \mathrm{m}$, mobile phase acetonitrile /water (Rankem) $(80: 20)$ (containing $0.125 \%$ acetic acid), flow $=1.0 \mathrm{ml} / \mathrm{min}$, UV/Vis detector $\left(\lambda_{\max }=280 \mathrm{~nm}\right)$. The separation of $\mathrm{NaCl}$ $(1.5 \mathrm{gm} / \mathrm{l})$ and $\mathrm{MgSO}_{4}(1 \mathrm{~g} / \mathrm{l})$ were monitored from the conductivity relationship, as it follows the linear co-relation with the concentes in removing the studied solutes was determined as follows:

$$
R=\left(1-\frac{C p}{C f}\right) \times 100
$$

where $R$ is the rejection in percentages, $C_{p}$ and $C_{f}$ are the concentration for permeate and the feed solution.

For the strong electrolytes, $C p$ and $C_{f}$ were correlated with the conductivity relationship and phenol compounds in water were monitored from the HPLC technique.

The flux was calculated from the relation:

$$
\text { Flux }=\frac{l}{t \times A}
$$

tindicates the volume of permeate in lit, $t$ in hours and $A$ is effective membrane area $\left(\mathrm{m}^{2}\right)$.

The molecular volume and dipole Theoretical methods to determine the structural parameters: Thircal AM1 method [8-9]. AM1 is moment of the phenol compounds were calculated using semi-empirical AM1 method [8-9]. AMl is a semi-empirical self-consistent fie in (Sals, $J_{i j}$ and $K_{i j}$ are neglected or parameterized, and only valence shell electrons are considered. The Hamiltonian operator takes the form:

$$
\widehat{H}_{\text {val }}=\sum_{i=1}^{N_{v}}\left(-\frac{1}{2} \Delta_{i}+V(i)\right)+\sum_{i=1}^{N_{x} 1} \sum_{j=i+1}^{N_{i j}} \frac{1}{r_{i j}}=\sum_{i=1}^{N_{i}} \widehat{H}_{\text {val }}^{\text {core }}(i)+\sum_{i=1}^{N_{k} 1} \sum_{j=i+1}^{N_{i}} \frac{1}{r_{i j}}
$$

where $N$ is the total number of valence electrons in the molecule, $V(i)$ is the potential energy of the $i^{\text {th }}$ ere $N_{v}$ is the the $i$ electron interation integrals of the one-center core orthogonalization corrections and the attractive penetration integrals of the ong to have useful Hamiltonian matrix elements. Semi-empirical methods like AM1 are accurate en

The dipole moment of these molecules, first the stable conformer have been predicted at AM1 level of theory. The possibility of intramolecular hydrogen bonding 

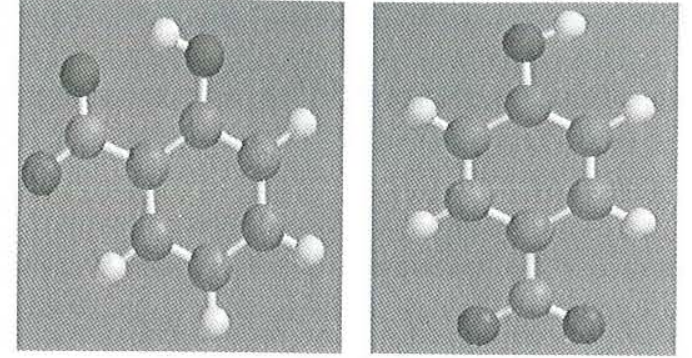

Figure 1 Structures of two nitro-phenol isomers

between the $\mathrm{OH}$ group and the nitro oxygen atom in 2-nitrophenol has been examined. The calculated results indicate that the H-bonded conformation is stable compared to the non H-bonded

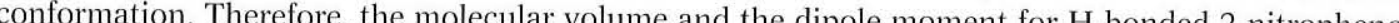
phenyl ring of both 2- and 4-nitrophenol (Figure 1). The AM1 calculated results suggest that the molecular volume for 2- and 4-nitrophenol are similar $\left(\sim 146.0 \AA^{3}\right)$, however, the dipole-moment is largely different for these two molecules.

\subsection{RESULTS AND DISCUSSION}

The preparation of asymmetric membrane is due to the diffusive exchange of water and $\mathrm{N}, \mathrm{N}$ dimethyl formamide which introduces liquid-liquid phase separation, i.e. the formation of polymer rich and a polymer lean phase in the casting solution. The successive solidification of the phase separated solution leads to a porous, asymmetric structure [12-16]. The water permeability (PWP) of solution leads to a porous, asymmetric structure [12-16]. The water permeability (PWP) of
the polysulfone membranes (MWCO 2, 70000) was checked and it was around $493.5 \mathrm{~lm}^{-2} \mathrm{~h}^{-1}$ at $0.34 \mathrm{MPa}$.

The cross-linked polyamide layer on the polysulfone support was prepared by interfacial polymerization technique. The monomers taken were 1, 3 phenylene diamine/piperizine (in water) and trimesoyl chloride (hexane) in different proportions. At the interface between the two solutions (water and hexane), a cohere diffusivity of the phenylene diamine/piperizine from the aqueous to organic phase is the important factor as reaction does not take place in the water phase, because a highly unfavorable partition coefficient for acid chloride limits its availability in the aqueous phase [17].

As the Table 2 suggests that with the decrease of the 1,3 phenylene diamine, the rejection of sodium chloride and magnesium sulfate decreases and the interesting feature is that Memb-II (from piperizine) shows the preferential selectivity of magnesium sulfate over the sodium chloride. Different

Table 2 Salt rejection performance data for the three membranes

\begin{tabular}{|c|c|c|c|}
\hline Membrane & Water flux (Flux, $\operatorname{lm}^{-2} h^{-1}$ ) & $\mathrm{NaCl} \% \mathrm{R}\left(\right.$ Flux, $\left.\operatorname{lm}^{-2} \mathrm{~h}^{-1}\right)$ & $\mathrm{MgSO}_{4} \% \mathrm{R}\left(\right.$ Flux, $\left.\mathrm{Im}^{-2} \mathrm{~h}^{-1}\right)$ \\
\hline Memb-I & 7.9 & $96.8(7.9)$ & $97(5.9)$ \\
\hline Memb-II & 25.7 & $85.7(23.7)$ & $82.7(25.7)$ \\
\hline Memb-III & 27.6 & $41(31.6)$ & $78(29.6)$ \\
\hline
\end{tabular}

transport mechanisms are in literature [18] to explain the salt rejection. The water flux order MembIII $>$ Memb-II $>$ Memb- I suggests that with the decrease of 1,3 phenylene diamine, the flux data increases and with piperizine (Memb-III), the membrane is forming loose network.

\subsection{Effect of Molecular Weight/Molecular Size of the Solutes}

The rejection performances of the organic solutes are mostly based on size exclusion. Mostly, the molecular size of the molecules can be assessed by their molecular weight. The molecular weight and molecular volumes of the solute molecules are enlisted in Table 3 . The rejection performance data of the molecules are listed in Figures 2 and 3 . The molecular weight and volume data justify the rejection order $\mathrm{R}_{\text {nitrophenol }}>\mathrm{R}_{\text {phenol. }}$. However, the rejection difference order of nitrophenols cannot be explained from the mol. weight/size point of view.

Table 3 Physical parameters of the molecules

\begin{tabular}{lccc} 
& Phenol & 2-nitro phenol & 4-nitro phenol \\
\hline Mol. Wt. & 94 & 139 & 139 \\
Mol. Volume $\left(\AA^{3}\right)$ & 117.1 & 146.12 & 147.69 \\
Dipole-moment $(D)$ & 1.233 & 4.33 & 5.264
\end{tabular}

90

80

70

60

$\simeq^{50}$

๙

30

20

10

0

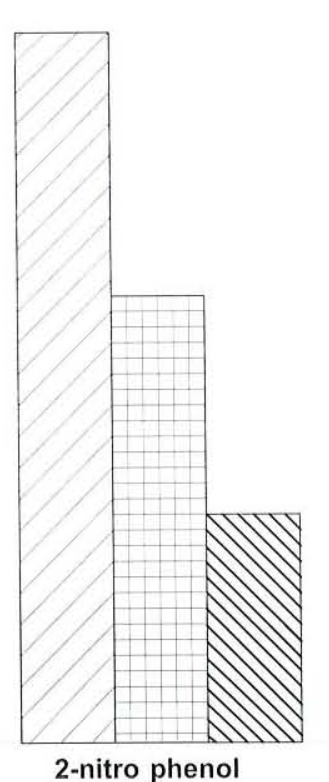

Phenol 2-nitro phenol $\square$ Memb-I

Memb-II

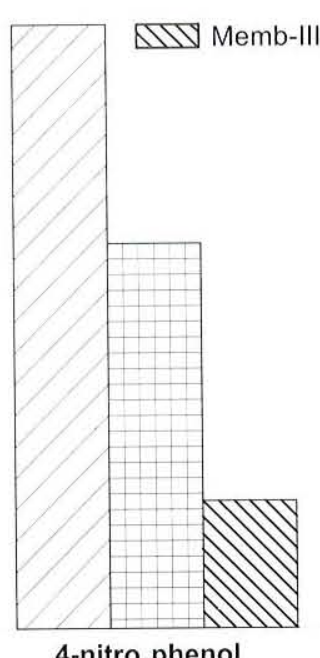

Figure 2 Rejection performance of phenol compounds (50 ppm) by membranes 
60

50

$\stackrel{\propto 2}{\circ} 40$

30

20

10

0

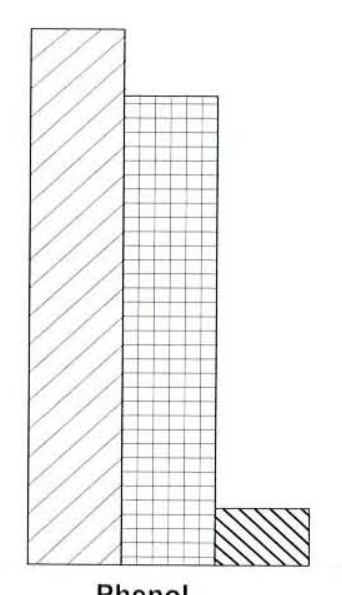

Phenol

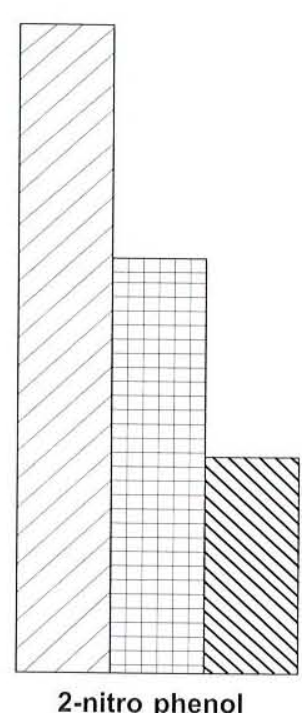

2-nitro phenol

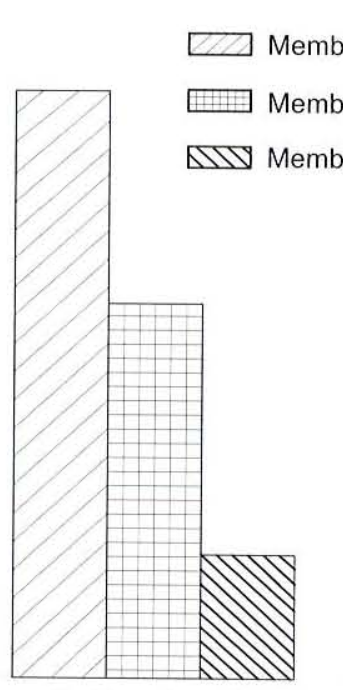

4-nitro phenol
Figure 3 Rejection performance of phenol compounds (25 ppm) by membranes

\subsection{Evaluation of Polarity of the Solute Molecules}

The polarity is a physical property which relates other physical parameters of the organic molecules The orientations of the molecules can be described from the polarity (represented by the dipole moment) of the molecule. Considering the dipole moment, the permeation of the organic molecules through the charged membrane could be explained. As the specified membranes are having negative charge due to the residual - $\mathrm{COOH}$ group in the trimesoyl chloride moiety of the cross-linked polyamide, the -OH groups of the solute molecules are oriented head-on to the membrane pore walls due to attractive interaction between the molecule polar centers and fixed charged groups on the membrane surface. As a result, the molecules are directed towards the pore and enters more easily into the membrane structure, i.e. the permeation of polar molecules will be favored though the membrane Here, the reje membranes ( $\sim 10 \%$ difference is there for $50 \mathrm{ppm}$ solution) can be explained from the dipole moment data from Figures 2 and 3 . The flux data of the membranes for different concentrations are shown in Table 4. Though the dipole moment values of nitrophenols are higher than the phenols, the rejection follows based on size exclusion, as the difference in size of phenol and nitro phenols are significant

Table 4 Flux data $\left(\mathrm{lm}^{-2} \mathrm{~h}^{-1}\right)$ of the membranes for the phenol compounds (50 ppm and $25 \mathrm{ppm}$ )

\begin{tabular}{lcccccc}
\hline & Phenol & $\begin{array}{c}\mathbf{5 0} \mathbf{~ p p m} \\
\text { 2-nitro } \\
\text { phenol }\end{array}$ & $\begin{array}{c}\text { 4-nitro } \\
\text { phenol }\end{array}$ & Phenol & $\begin{array}{c}\text { 25 } \mathbf{~ p p m ~} \\
\text { phitro }\end{array}$ & $\begin{array}{c}\text { 4-nitro } \\
\text { phenol }\end{array}$ \\
\hline Memb-I & 6.5 & 5.9 & 6.9 & 6.3 & 6.3 & 7.3 \\
Memb-II & 23.7 & 22.7 & 14.8 & 24 & 22.7 & 16.8 \\
Memb-III & 33.6 & 32.9 & 35.9 & 35.9 & 32.9 & 33.6 \\
\hline
\end{tabular}

\subsection{Effect of Nature of the Membranes}

As shown in Table 1, the membranes used for the experiment are of different nature. The salt rejection performance of the membranes decreases as the 1,3 phenylene diamine content of the membranes. However, the salt rejection performance of the piperizine based membranes is the lowest one. The water flux data suggests that piperizine based membranes are having loose network with respect to water flux data suggests that piperizine based membranes are having loose network with respect to
1,3 phenylene diamine and their mixed one. As the salt rejection decreases, the rejection of the phenol compounds also decreases.

\subsection{Effect of Concentration of the Phenol Solutes}

The membrane performance regarding the phenol solutes depends upon the concentration of the phenol compounds. Figures 2 and 3 indicate a positive correlation between concentration and rejection. The rejection ability of the membranes is diminishing with the decrease in concentration of the nitrophenols.

\subsection{CONCLUSIONS}

(i) The 1, 3 phenylene diamine based membranes are showing the highest salt rejection compared to the piperizine and their mixture (1:1). The phenol rejections of the membranes are also following the same order as the salt rejection. The piperizine based membrane is being relatively of loose network, the performance order in terms of rejection is Memb-I > Memb-II $>$ Memb-III.

(ii) Separation of un-dissociated organic compounds is controlled by the sieving effect of the membranes. The molecular weight and volume are the usual parameters to assess the size of membranes. The molecular weight and volume are the usual parameters to assess the size of the molecules. The study
molecular weight/volume.

(iii) The difference in rejection of the isomers $\left(\mathrm{R}_{2 \text {-nitro phenol }}>\mathrm{R}_{4 \text {-nitro phenol }}\right)$ is due to the polarity difference of the specified compounds. As the dipole moment of 2-nitro phenol is less than 4-nitro phenol, the 4-nitro phenol molecules pass through the negatively charged membrane relatively easier. The rejection performance shows the direct relationship with the concentration of the phenol compounds.

\section{ACKNOWLEDGEMENT}

This research is supported by the International Foundation for Science, Sweden.

\section{REFERENCES}

[1] Ozaki, H. and H. Li. 2002. Rejection of Organic Compounds by Ultra-low Pressure Reverse Osmosis Membrane. Water Research. 36: 123-130.

[2] Kiso, Y., T. Kon, T. Kitao, and K. Nishimura. 2001. Rejection Properties of Alkyl Phthalates with Nanofiltration Membranes. J. Membr. Sci. 182: 205-214. 
[3] Bhattacharya, A., P. Ray, H. Brahmbhatt, K. N. Vyas, S. V. Joshi, C. V. Devmurari, and J. J. Trivedi. 2006. Study in Pesticides Removal Performance by Low Pressure Reverse Osmosis Membranes. J. Appl. Polym. Sc. 102: 3575-3579.

[4] Vander Bruggen, B. and C. Vandecasstelle. 2003. Removal of Pollutants from Surface Water and Ground Water by Nanofiltration: Overview of Possible Applications in the Drinking Water Industry. Environmental Pollution. 122: 435-445.

[5] Peterson, R. J. 1993. Composite Reverse Osmosis and Nanofiltration Membranes. J. Membr. Sci. 83: 81-150.

[6] Bhattacharya, A., K. M. Popat, B. Ganguly, H. Brahmbhatt, and Y. Kumar. Remediation of Phenol Compounds from Water Using Low Pressure Reverse Osmosis Membranes. Communicated.

[7] Bhattacharya, A. 2005. Remediation of Pesticides Polluted Water Through Membranes. Sep. Purif. Rev. 35: 1-35.

[8] Dewar, M. J. S., E. G. Zoebisch, E. F. Healy, and J. J. P. Stewart. 1985. Development and Use of Quantum Mechanical Molecular Models. 76. AM1: A New General Purpose Quantum Mechanical Molecular Model. J. Am. Chem. Soc. 107: 3902-3909.

[9] Titan, Wavefunction, Inc, 18401 Von Karman Avenue, Suite 370, Irvine CA 92612 USA, Schrodinger, Inc., 1500 SW First Avenue, Suite 1180, Portland, OR 97201 USA.

[10] Levine, I. N. 2000. Quantum Chemistry. 5th ed. Upper Saddle River: Prentice Hall.

[11] Zerner, M. C. 1991. In Reviews in Computational Chemistry. Edited by K. B. Lipkowitz, D. B. Boyd. VCH: New York. 313.

[12] Kim, J. H., B. R. Min, J. Won, H. C. Park, and Y. S. Kang. 2001. Phase Behavior and Mechanism of Membrane Formation for Polyimide/DMSO/Water System. J. Membr. Sc. 187: 47-55.

[13] Gohil, J. M., A. Bhattacharya, and P. Ray. 2004. Effect of Polymeric Surface-active Agents in the Phase Inversion Step of Asymmetric Membrane Formation. J. Surf. Sci. Tech. 20(1-2): 1-7.

[14] Radvanovic, P. S., W. Thiel, and S. T. Hwang. 1992. Formation of Asymmetric Polysulfone Membranes by Immersion Precipitation. Part I. Modelling Mass Transport During Gelation. J. Membr. Sci. 65(3): 213-229.

[15] Radvanovic, P. S., W. Thiel, and S. T. Hwang. 1992. Formation of Asymmetric Polysulfone Membranes by Immersion Precipitation. Part II. The Effects of Casting Solution and Gelation Bath Compositions on Membrane Structure and Skin Formation. J. Membr. Sci. 65(3): 231246.

[16] Stropnik, C. and V. Kaiser. 2002. Polymeric Membranes Preparation by Wet Phase Separation: Mechanisms and Elementary Processes. Desalination. 145(1-3): 1-10.

[17] Morgan, P. W. 1965 Condensation Polymers: By Interfacial and Solution Methods. NY: Interscience Publishers.

[18] Bhattacharya, A. and P. Ghosh. 2004. Nanofiltration and Reverse Osmosis Membranes: Theory and Application in Separation of Electrolytes. Rev. Chem. Eng. 20(1-2): 111-173. 